\title{
Microscale Mineral and Pore Structure Characterization of the Low-Permeability Sandstone in the Ordos Basin, China
}

\author{
Jie Gao $\mathbb{D}^{1},{ }^{1}$ Zhen Sun, ${ }^{2}$ Jianping Liu, ${ }^{3}$ Chenyang Zhao, ${ }^{3}$ Dazhong Ren, ${ }^{4}$ Rongjun Zhang, \\ Tingting Li, ${ }^{1}$ and Dengke Liu $\oplus^{5}$ \\ ${ }^{1}$ School of Civil Engineering \& Geodesy, Shaanxi College of Communication Technology, Xi'an 710018, China \\ ${ }^{2}$ No. 6 Gas Production Plant, Changqing Oilfield Company, PetroChina, Yanan 716000, China \\ ${ }^{3}$ Exploration and Development Research Institute, PetroChina Changqing Oilfield Company, Xi'an 710018, China \\ ${ }^{4} X i$ 'an Key Laboratory of Tight Oil (Shale Oil) Development, Xi'an Shiyou University, Xi'an 710065, China \\ ${ }^{5}$ School of Human Settlement and Civil Engineering, Xi'an Jiaotong University, Xi'an 710049, China \\ Correspondence should be addressed to Dengke Liu; liudengke02@126.com
}

Received 27 May 2021; Revised 22 June 2021; Accepted 1 July 2021; Published 10 July 2021

Academic Editor: Xiaohu Zhang

Copyright (c) 2021 Jie Gao et al. This is an open access article distributed under the Creative Commons Attribution License, which permits unrestricted use, distribution, and reproduction in any medium, provided the original work is properly cited.

\begin{abstract}
Given the insufficient understanding of the characteristics and controlling factors of the low-permeability sandstone reservoir in the Heshui area, the Ordos Basin, the present study examined the microscale mineral and pore structure of Chang 2 reservoir. It analyzed its major controlling factors using a series of methods, including imaging and indirect methods. The results show that the rocks of Chang 2 reservoir in the study area are dominated by lithic arkose and feldspathic detritus quartz sandstone. The reservoir space develops intragranular pores, feldspar dissolved pores, lithic dissolved pores, and intercrystallite pores. Microcracks can occasionally be found. The average porosity is $10.5 \%$, and the average permeability is $2.2 \mathrm{mD}$, featuring a low-porosity-ultralowpermeability reservoir. During the reservoir development, traps formed by small-scale nose-shaped uplifts resulting from the tectonic effects provide opportunities for good reservoir space. Sedimentation and diagenetic processes control the degree of development and direction of the evolution of reservoir porosity to a certain degree. Multisegment capillary pressure curve and long missing zone were corresponding to relatively good pore-throat structures. Illite was the predominant diagenetic clay minerals that determine the reservoir quality. These three effects all contribute to the overall development of the reservoir.
\end{abstract}

\section{Introduction}

The recent waterflooding and chemical flooding advancements have significantly increased the low-permeability sandstone reservoirs $[1,2]$. The low-permeability sandstone reservoir in the Heshui area, located in the Ordos Basin in China, is now one of the China's most significant hydrocarbon reservoirs [3]. In recent years, through the exploration and evaluation of the Heshui area, scholars have found that the yield of Chang 2 reservoir in oil tests was relatively high. This finding is vital for increasing China's oil production and reserve, demonstrating the vast potential for future prospection and development [4, 5]. However, compared with massive studies of other areas, the Heshui area study is still limited and is in the primary stages [4].
Previous studies in this area were primarily concerned with the oil groups from Chang 8 to Chang 6. A lack of systematic investigations of the characteristics, formation, and controlling factors in Chang 2 significantly restrained the target evaluation and optimization analysis [6, 7].

Consequently, the mineralogical, diagenetic, tectonic, and pore structure characterization of Chang 2 sandstones are still poorly understood. Mineral composition, physical properties, and pore size distributions are the most significant parameters in sandstones that affect the mechanical, storage, and transport properties of the sandstones [8-10]. Compared to conventional reservoirs, the pore networks in sandstone reservoirs are more complicated because of the abundance of microscale heterogenetic distributions of minerals [11]. 
Composition, proportion, and distribution are the essential characteristics of the minerals [12]. Pores could be divided into different groups based on various category criteria, and the criterion proposed by the IUPAC is the most common one [13]. Many scholars have applied this criterion to analyze the pore networks. In contrast, this criterion is not a generally accepted way for each research, and the pore network classification needs to base on actual demand. Thin section (TS) and scanning electron microscopy (SEM) are the image analysis methods to determine the mineralogical characteristics qualitatively and quantitatively [14]. Pressure-controlled mercury intrusion and rate-controlled mercury intrusion (PCMI/RCMI) are the standard techniques to quantify the pore size distributions $[15,16]$. Combining PCMI and RCMI can give us information about the whole pore size distributions of more than $3.6 \mathrm{~nm}$ [17].

Based on the development status of low- (ultralow-) permeability reservoirs and the characteristics of Chang 2 in the Heshui area, the present research aims to provide a comprehensive and systematic study of its physical properties and the microscopic pore structure, utilizing copious experimental methods, including core observation, TS, SEM, PCMI, and RCMI methods. Besides, the present research also examined the main controlling factors affecting the reservoir, which is of great significance for future research on the Yanchang Formation and further expansion of the domains in oil-gas exploration in the central basin $[18,19]$.

\section{Methodology}

2.1. Geological Background. Heshui area is located in the southern part of the Shaanbei Slope (Northern Shaanxi Slope) and the Tianhuan Depression in the Ordos Basin. Its tectonic evolution is inseparable from the overall tectonic background of the Ordos block. The general structure of the Heshui area features a gentile monocline oriented on an east-west axis, without any faults or large-scale basement uplifts. The monoclinic slope is generally less than $1^{\circ}$, and the average gradient is about $6 \mathrm{~m} / \mathrm{km}$. Small nose-shaped uplifts with an amplitude of 10 to $20 \mathrm{~m}$ were formed in local areas due to differential compaction [20]. These uplifts tend to have graduate tilts at the two ends and are largely axisymmetric. The closed areas generally do not exceed $10 \mathrm{~km}^{2}$ in size. The angle is directional in specific ways and is regularly distributed [21]. Although the structures above in the study area affect the distribution of oil pools, their influence is only marginal.

The Chang 2 oil group has undergone a certain degree of denudation on the southern and southwestern margins of the basin, but it is still preserved. The lithological features of the oil group tend to be roughly coarse-grained in the north and fine-grained in the south, with an average thickness of 110 to $120 \mathrm{~m}$ (Figure 1). The overall petrological characteristics are as follows: light gray and brown and fine- and medium-fine-grained sandstone intercalated with dark shales in typology. Typically, the rocks are massive, with trivial and thin stratification, dominated by argillaceous and calcareous cementation.
2.2. Experimental Procedures. An optical microscope is applied to identify the mineral types and quantify the mineral's composition and proportion. Before the tests, the rocks were sliced to pieces and covered by glass. The $E-c$ system was applied to analyze the mineral characteristics quantitatively.

Zeiss GeminiSEM 500 was used to analyze the mineralogical distributions of the samples. Before the tests, the samples were first polished as a cube, milled via argon ion. After those steps, the samples were finally coated with carbon.

Micromertrics AutoPore 9420 mercury porosimeter was used to perform the PCMI experiments. The samples were first dried for $12 \mathrm{~h}$ and then saturated by lipophilic remover. Finally, the samples were put into the apparatus and the relationship between capillary pressure and mercury saturation was tested.

Automated System for Pore Examination ASPE-730 was used to conduct the RCMI tests. The pre-exam procedures were the same as that of PCMI. However, in this test, the maximum pressure was not over $6.2 \mathrm{MPa}$, corresponding to the pore radius of $0.12 \mu \mathrm{m}$.

\section{Results and Discussion}

3.1. Petrological Characteristics. According to the statistics collected from core observation, thin-section casting, and other analytical processes, rocks in the study area are mainly medium gray, fine-grained sandstones, fine-grained sandstones, and fine siltstones, with an average particle size between 0.1 and $0.35 \mathrm{~mm}$ and a maximum of $0.5 \mathrm{~mm}$. The rocks are dominated by lithic arkose and feldspathic detritus quartz sandstones (Figure 2).

The total amount of debris is between $74.6 \%$ and $90 \%$, with an average of $84.4 \%$. Among the debris, the content of quartz is $24.6 \%$ to $60 \%$, with an average of $44.9 \%$; the range of feldspar is $12 \%$ to $39 \%$, with an average of $22.8 \%$; the content of cuttings is $10 \%$ to $34.2 \%$, with an average of $19.2 \%$ (Table S1).

The degree of sorting is good to medium. The degree of rounding is mainly subangular to subcircular; the main types of cementing are enlarged-porous cementing, porous cementing, pore-increasing cementing, and pore-film cementing.

The overall content of interstitials is not high, mainly composed of cement ranging from $10 \%$ to $24.5 \%$, with an average of $16.2 \%$. Most of the cementations are authigenic clay materials, followed by feldspathic components and pyrites. Matrix only takes up a deficient composition (Table S2).

3.2. Diagenesis and Diagenetic Stages. Chang 2 reservoir in the study area contains relatively high plastic debris such as phyllite, schist, and mica. Feldspar dissolved pores and lithic dissolved pores are fairly developed, in which diagenetic fractures can be found occasionally. Kaolinite, illite, and chlorite in the authigenic clay minerals are ubiquitous, with high carbonate content. Quartz is secondarily enlarged and contains authigenic quartz grains. This shows that the effect of compaction and pressure solution was strong in this period. The cement mainly comprises authigenic clay 


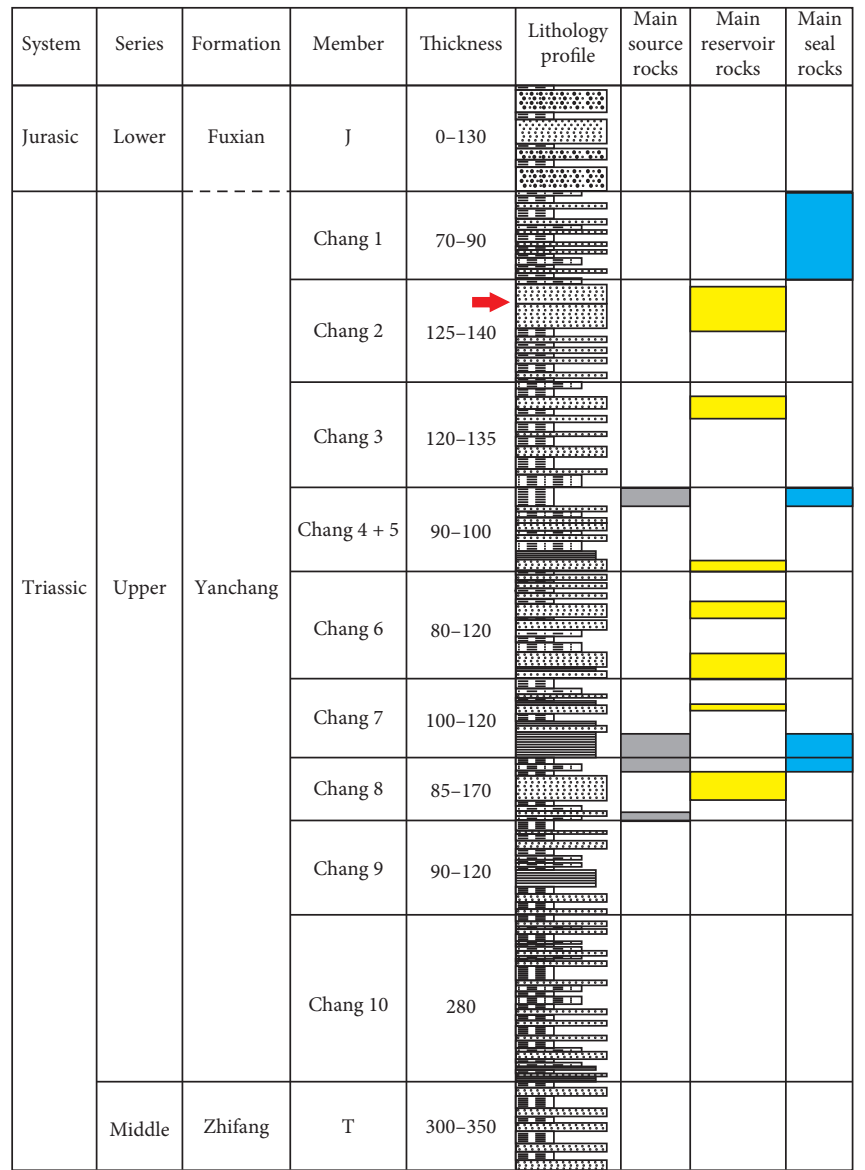

Sudstone
Sandy conglomerate
Siltstone

Siltstone

Sandstone Shale

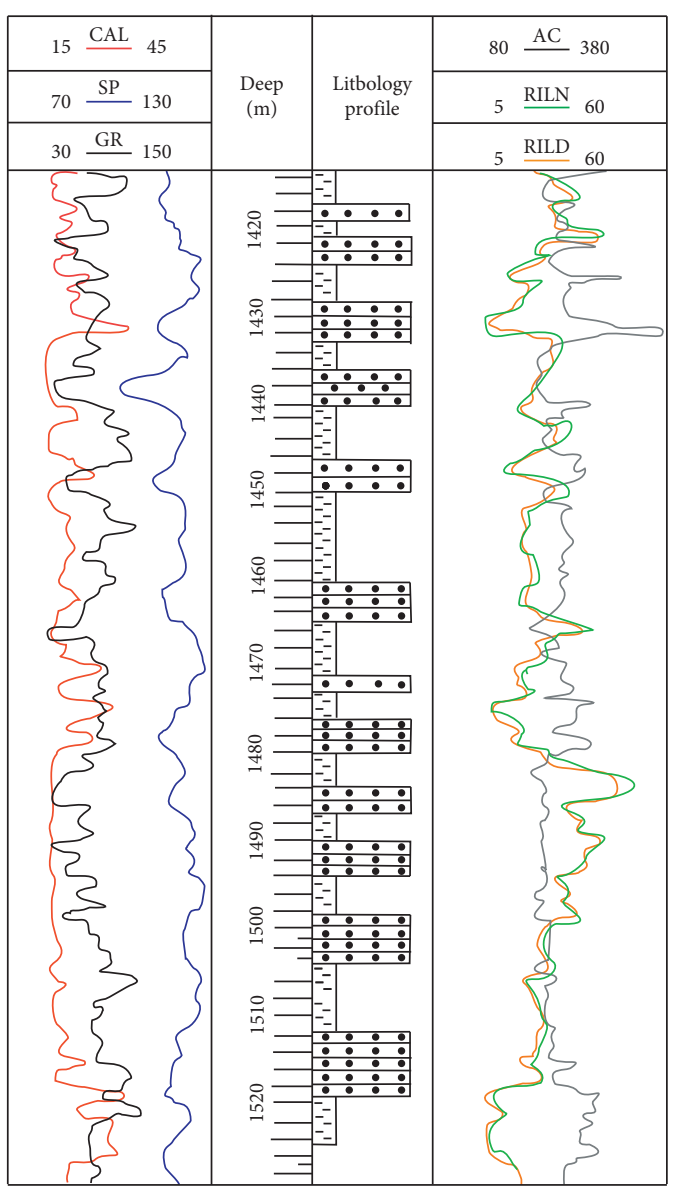

(a)

(b)

FIgURE 1: (a) Lithology profile of the Yanchang Formation and (b) well-logging data of Chang 2 reservoir in the study area [22].

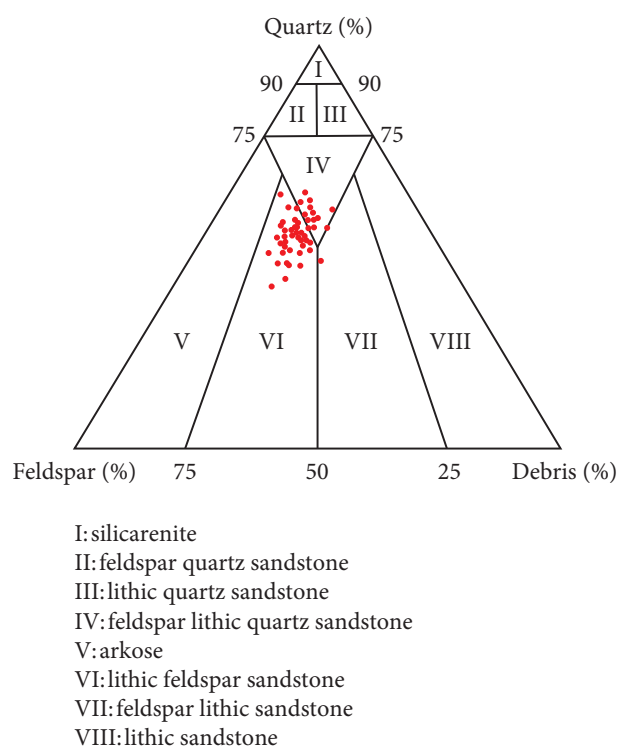

FIgURE 2: Ternary diagram of mineralogy in Chang 2 sandstone. minerals and carbonate minerals, and the content of kaolinite in sandstone is relatively high. Carbonate and siliceous cementation are common, while metasomatism and fracturing are relatively common (Figure 3). Among the aforementioned diagenetic processes, the dissolution of feldspar and debris and the metasomatism of kaolinite are beneficial to forming good reservoirs.

In contrast, other kinds of processes are likely to cause damage to the reservoirs. The diagenetic sequence of the reservoir is compaction $\longrightarrow$ chloriteization $\longrightarrow$ quartz enlargement $\longrightarrow$ calcite precipitation $\longrightarrow$ organic acid generation $\longrightarrow$ feldspar, debris, and calcite dissolution $\longrightarrow$ iron calcite precipitation $\longrightarrow$ oil emplacement. The above characteristics indicate that the diagenetic stage of the sandstones in the study area is amidst stages A to B of the middle diagenetic stage.

3.3. Physical Characteristics of the Reservoir. The statistical analysis (Figure 4(a)) show that the reservoir porosity is mainly between $7 \%$ and $13 \%$ with an average of $10.5 \%$, the 


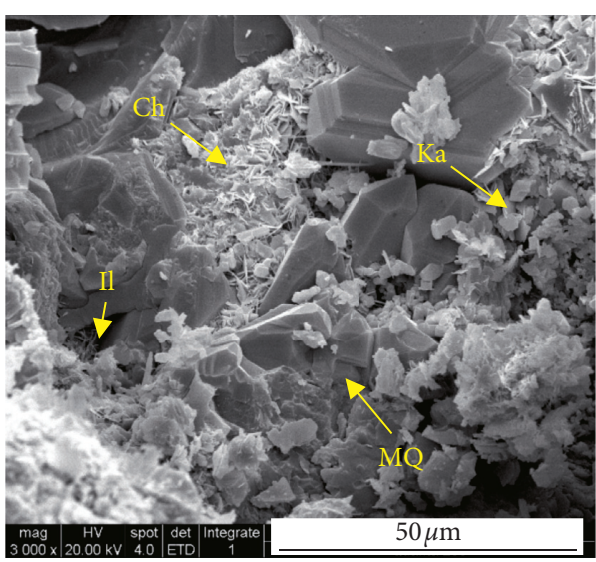

(a)

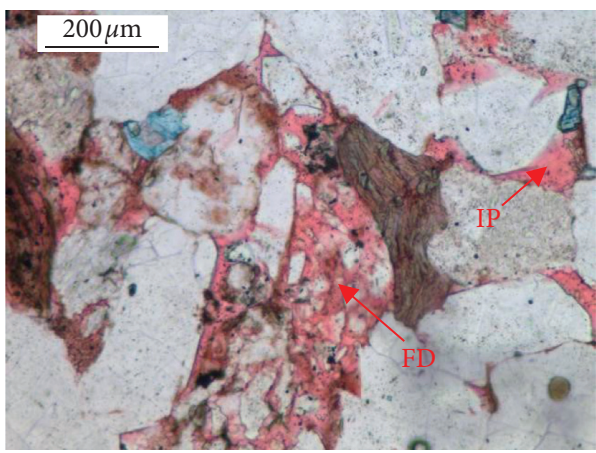

(c)

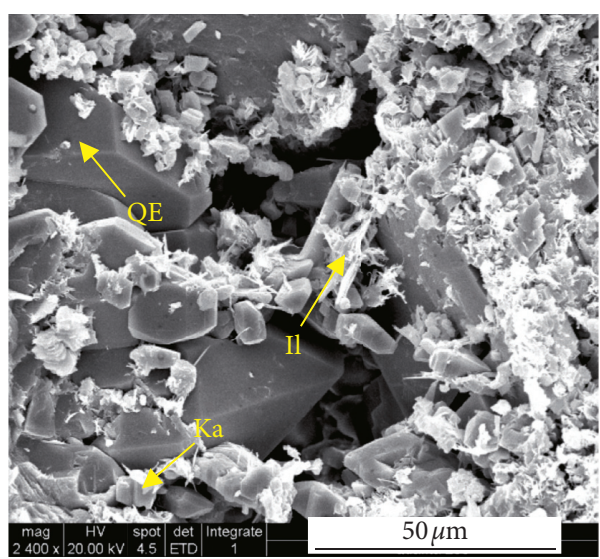

(b)

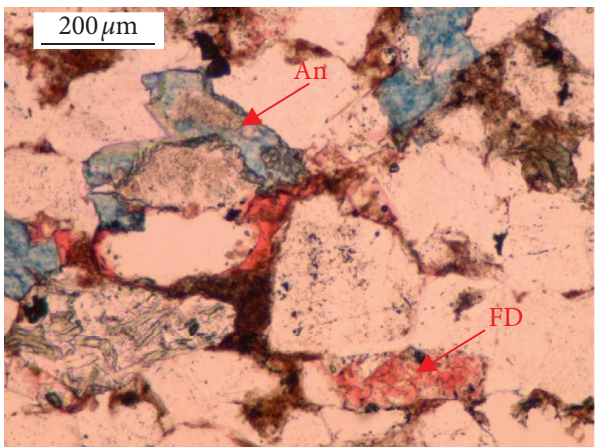

(d)

FIgURE 3: Diagenesis of Chang 2 reservoir in the study area. (a) Cementation of microcrystalline quartz (MQ), kaolinite (Ka), illite (Il), and chlorite $(\mathrm{Ch})(\mathrm{N} 39,1218.6 \mathrm{~m})$; (b) quartz enlargement (QE), intergranular kaolinite (Ka), and illite cementation (Il) (Z140, $1473.9 \mathrm{~m})$; (c) feldspar dissolution (FD) and intergranular pores (IP) (N9, $1210 \mathrm{~m})$; (d) ankerite (An) and feldspar dissolution (FD) (Z140, 1473.9 m).

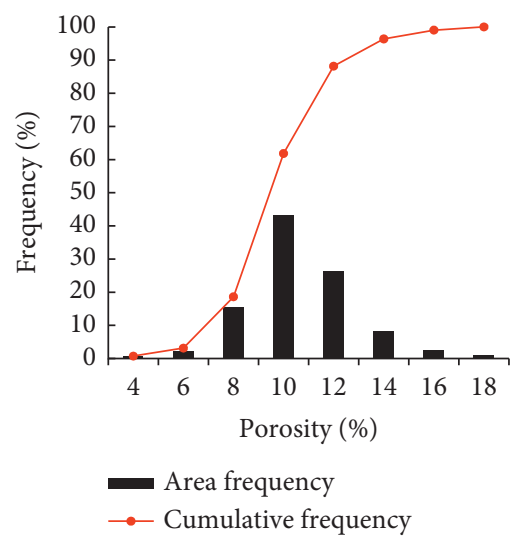

(a)

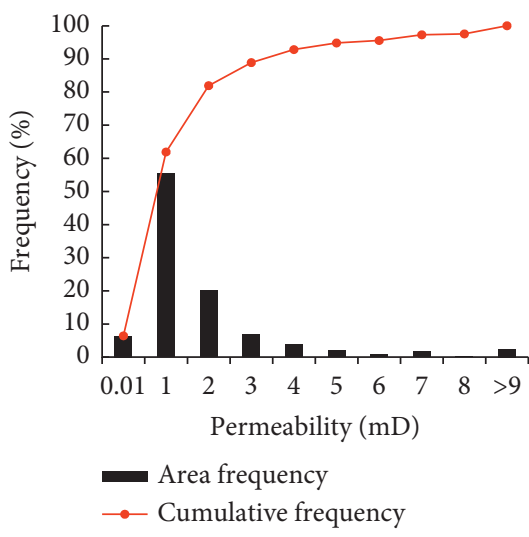

(b)

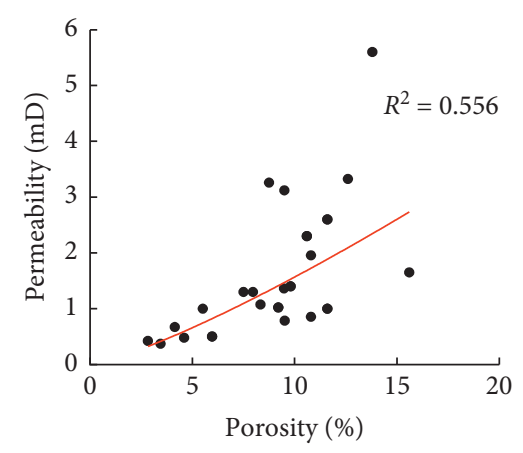

(c)

FIGURE 4: The distribution of (a) porosity, (b) permeability, and (c) the porosity-permeability relationship of Chang 2 reservoir in the study area.

main frequency is distributed in the $5 \%$ to $15 \%$ section, accounting for $76 \%$ of the total distribution. The permeability is mainly distributed between 0.15 and $3 \mathrm{mD}$, and the average is $2.2 \mathrm{mD}$. The frequency distribution is mainly between 0.5 and $5 \mathrm{mD}$, accounting for $56.7 \%$ of the total distribution. The above results suggest that the target reservoir in Heshui area belongs to low-porosity-ultralowpermeability reservoirs [23]. Figure 4(c) shows a positive correlation between the porosity and permeability $\left(R^{2}=0.556\right)$, indicating good physical characteristics. 
3.4. Microstructure and Characteristics of the Reservoir. The sandstones in the study area mainly develops intergranular pores with an average content of $1.8 \%$, followed by feldspar dissolved pores with an average content of $0.9 \%$, then by lithic dissolved pores of $0.2 \%$, and then by intercrystalline pores of $0.1 \%$. Microcracks can occasionally be found. The average aperture ratio is $3.2 \%$. The average pore diameter mainly falls between 30 and $80 \mu \mathrm{m}$. The main types of pore combination are dissolved pore-intergranular pore type, microporous type, intergranular pore-dissolved pore type, and intergranular pore type (Figure 5). The main types of throats are lamellar throats, and a small number of constricted throats also exist. The tortuosity of the mainstream throat is relatively low-relatively high (Figure 6), and the average throat radius is $0.93 \mu \mathrm{m}$. The sorting coefficient is 1.49 , and the relative sorting coefficient is 0.14 . The type of pore-throat combination is mainly mesopore-fine pore-fine throat type, and the coordination number of throats mainly falls between 2 and 6 , and the connectivity between throat and pore is poor.

The high-pressure mercury intrusion experiment (see Table S3 for mercury intrusion parameters) shows that the pore-throat radius of the reservoir is relatively small, and the pore-throat volume is relatively large. Besides, the throat is relatively thin and small. The degree of sorting is moderate to low. The residual mercury saturation is relatively high, and the displacement pressure is relatively low. The maximum mercury saturation is average. This shows that the storage ability of the study area is average, the filtration capacity is relatively poor, and the connected storage space is relatively small. Besides, we also conducted an oil-water phase permeability experiment, which shows that rocks in the study area are neutral-weakly hydrophilic, and the oil-water displacement efficiency is low.

3.5. Major Controlling Factors. Based on the formation and distribution characteristics of the reservoirs, it is believed that the development and spatial distribution of Chang 2 reservoir in the study area are comprehensively controlled by tectonics, sedimentation, and diagenetic effects.

The study area is in the Shaanbei Monocline. Since it was affected by denudation and differential compaction, smallscale nose-shaped uplifts are developed in local areas. These nose-like uplifts and the belt-like sandstone reservoirs distributed in the up-dip direction near NE-SW (Figure 7), together with the interriver argillaceous lithology, are mutually configured to form a good trap [24]. Chang 2 reservoir in the study area is controlled by lithology and tectonism, and the types of reservoirs are mainly lithology-tectonism composite reservoirs. In the up-dip direction of the structure, a good trap is easily formed due to the compaction of the sand body. However, we also need to point out that not all reservoirs in high structural positions can become good oil layers. The reasons for this need to be analyzed in conjunction with sedimentation and diagenesis.

Sedimentation controls the spatial distribution of various sedimentary environments and their products on the macroscopic level and the physical properties of rocks on the microscopic level. According to the sedimentary facies analysis and sand distribution characteristics of Chang 2 reservoir in the study area, it is found that the target layer in this area belongs to the delta front deposit, and the sand body extends far, running through the role area $[25,26]$. Large-area underwater distributary channels, braided channels, and estuary bar sand bodies with larger thickness and better physical properties provide the possibility of forming oil layers. We also found that the microfacies sand bodies of the estuary bar have more refined grains and uniform structure, with the primary intergranular pores accounting for about $80 \%$. The dissolved pores were developed, which accounts for about $15 \%$. The physical properties data show that the study area is a favorable reservoir facies zone, but the spread area is small and cannot be used as the main force zone. The sand body in the microfacies at the estuary dam is fine-grained, well-sorted, with primary intergranular pores accounting for $60 \%$ to $80 \%$. Dissolved pores area developed, accounting for about $20 \%$ of pores. Porosity is greater than $10 \%$. Permeability value is greater than $1 \mathrm{mD}$, and the oil-bearing characteristic is generally good. These regions can serve as favorable reservoir facies belts. Due to strong reservoir heterogeneity, the physical properties change, resulting in poor oil content and storage performance in the flanks of the underwater distributary channel and the distributary bays.

We were taking two samples from different sedimentary facies belts as an instance (Figure 8). There are two platforms and a low missing zone for the samples from underwater distributary channels, while single long platforms and short, a missing zone for the samples from estuary bar. A heterogeneous hydrodynamic environment led to high heterogeneous grain distributions and then caused the complex pore-throat structures. However, due to the strong hydrodynamic condition, the larger pores were relatively developed (Figures 8(a) and 8(c)). Compared to underwater distributary channels, the sands from the estuary bar have more homogeneous grain distributions. The long platform indicates the relatively uniformly distributed grain sizes, and the short missing zone suggested the stable hydrodynamic condition. However, weak hydrodynamic streams generally could not carry large grains, leading to poor physical properties and simple porethroat networks with low average radius (Figures 8 (b) and $8(\mathrm{~d})$ ).

Diagenesis controls the evolution direction of pores in the process of burial diagenesis and is of great significance to reservoir evaluation and prediction $[27,28]$. The diagenetic type of the target layer in the study area is very complicated. According to microscopic observation and statistics, the diagenetic processes exhibit strong, compact compaction, dissolution, and cementation effects (Figure 9). Among those processes, the dissolution of feldspar and debris and the metasomatism of kaolinite are beneficial to forming good reservoirs. In contrast, other types are likely to cause damage to the reservoirs. 


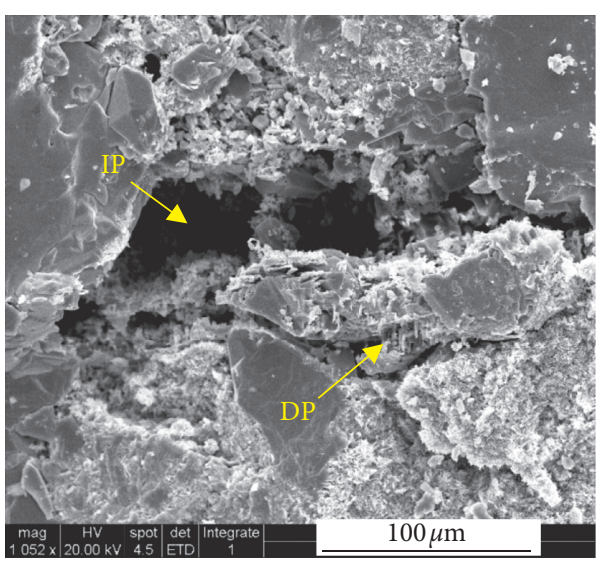

(a)

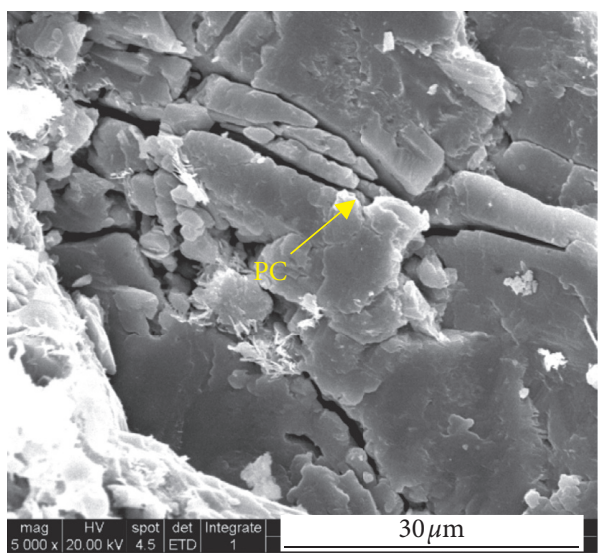

(c)

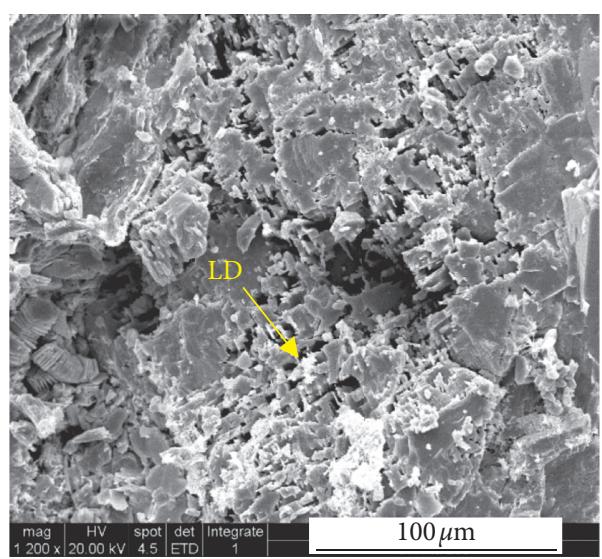

(b)

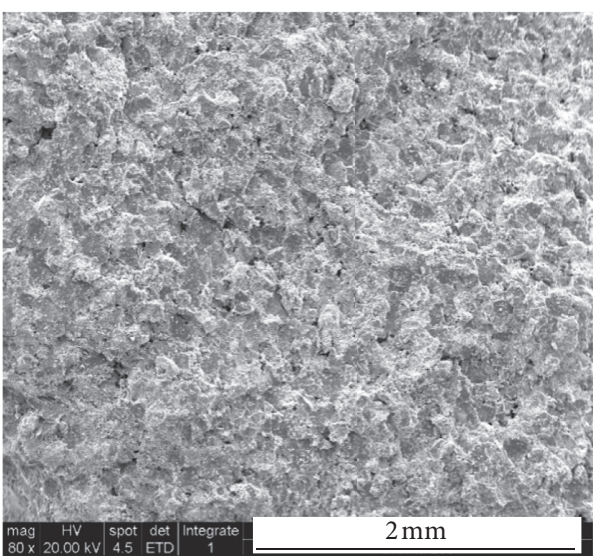

(d)

Figure 5: Pore types of Chang 2 reservoir in the study area. (a) Residual intergranular pores (IP) and dissolution pores (DP) (Z140, $1473.4 \mathrm{~m})$; (b) particle leaching dissolution pores (LD) (Z140, 1473.4 m); (c) particle cracks (PC) (Z140, 1473.9 m); (d) overall, poor pore development (Z140, $1473.9 \mathrm{~m})$.

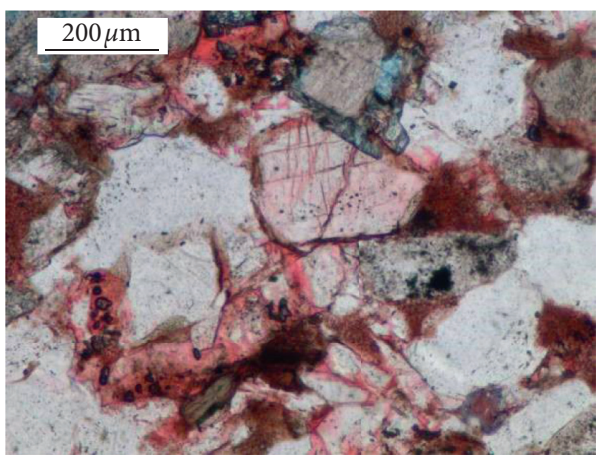

(a)

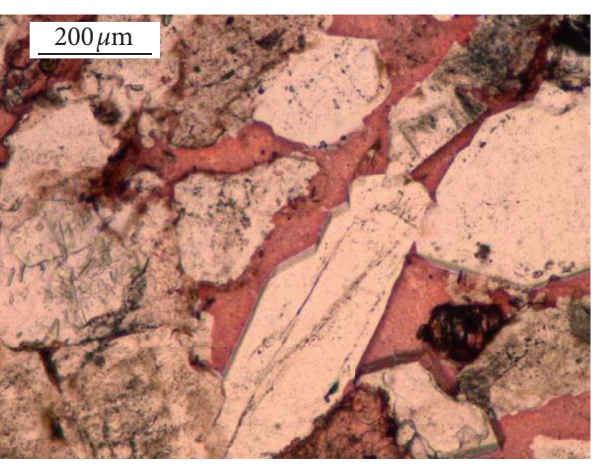

(b)

Figure 6: Throat types of Chang 2 reservoir in the study area. (a) Flake throat (N39, 1218.6 m) and (b) necking throat (Z48, 1291.1 m). 


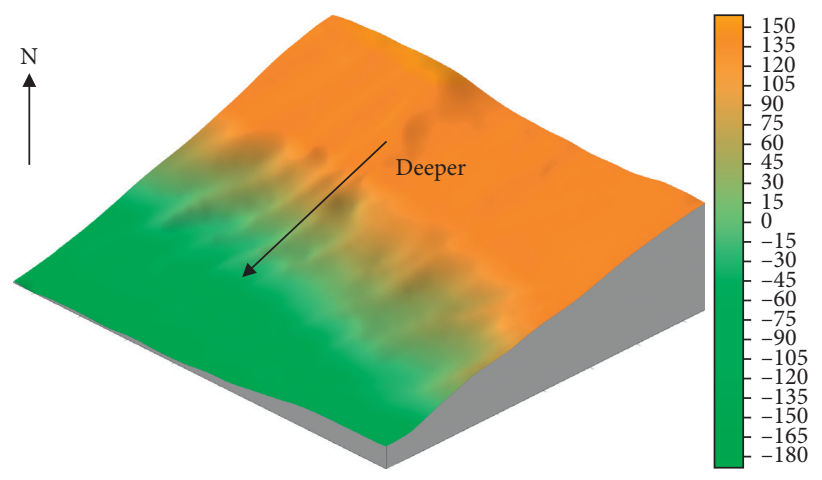

FIgURE 7: Top surface structure of Chang 2.

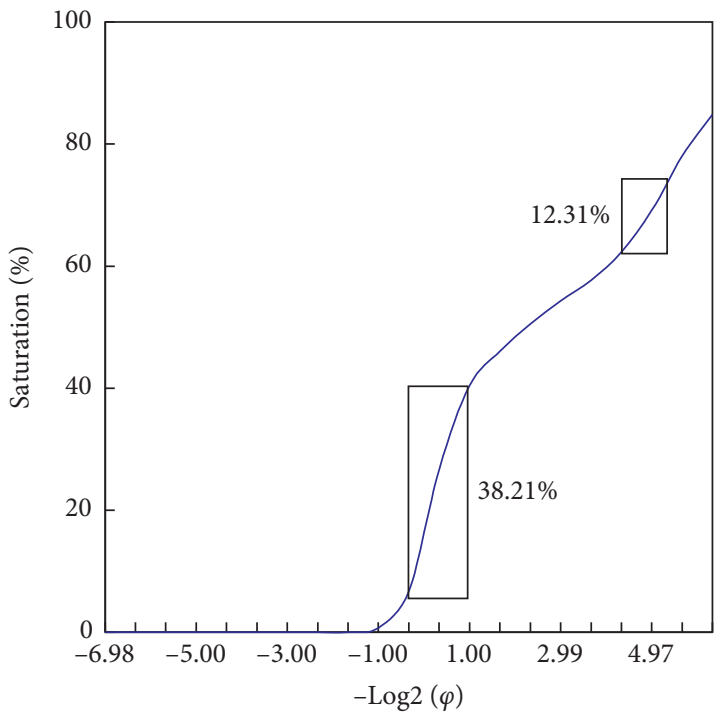

(a)

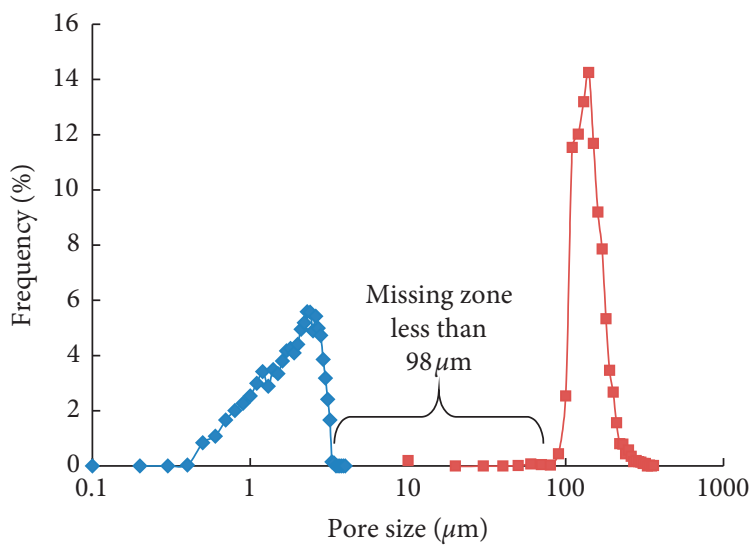

$\rightarrow$ Pore

$\longrightarrow$ Throat

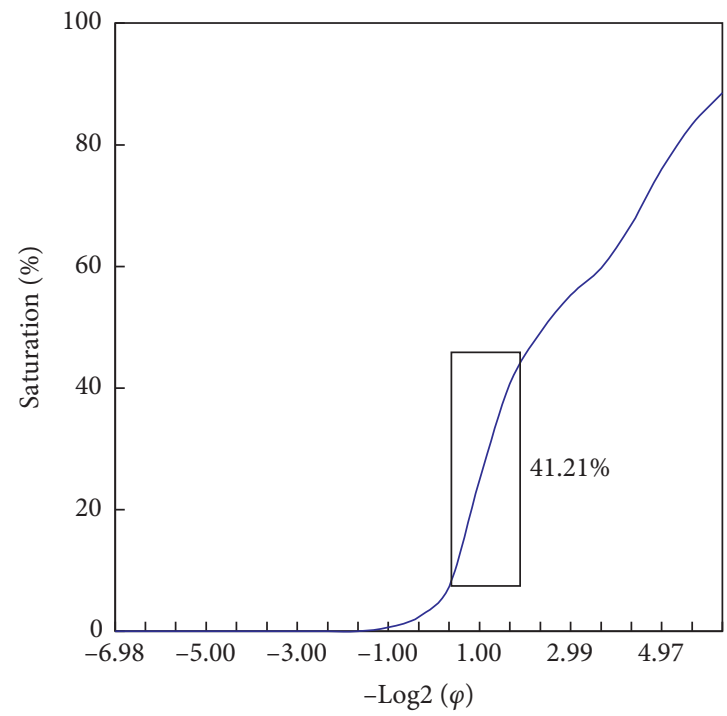

(b)

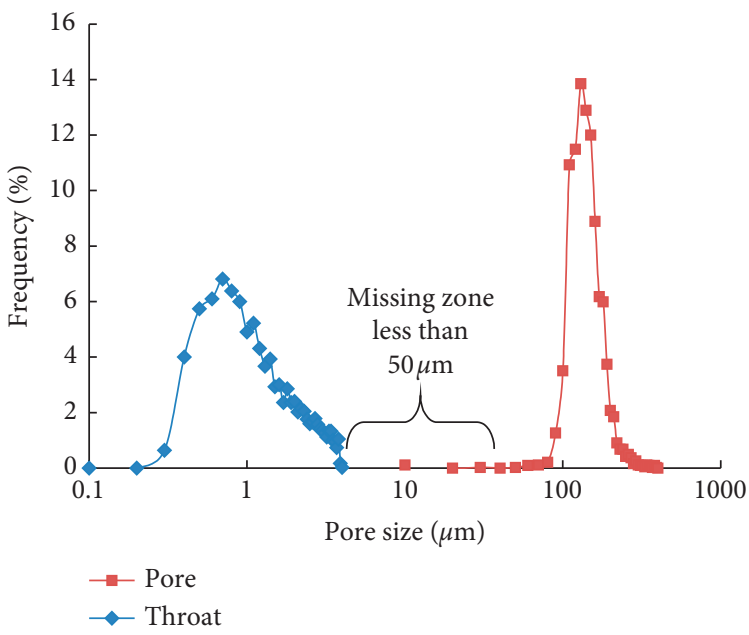

(d)

(c)

FIgure 8: Cumulative pore size distributions from PCMI and RCMI. 


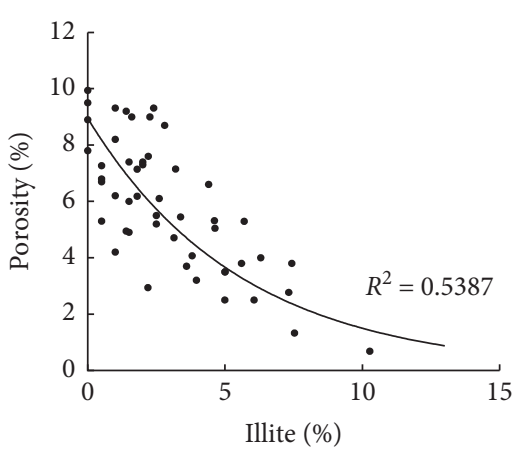

(a)

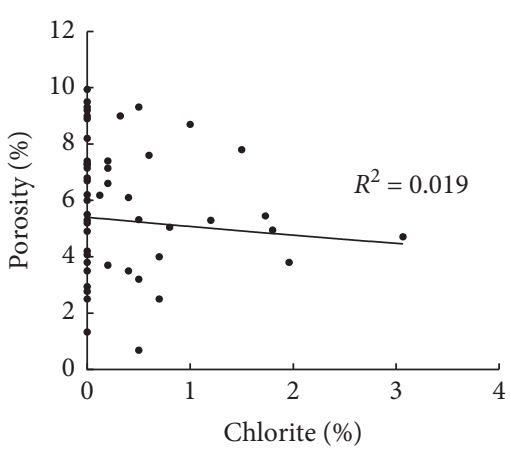

(b)

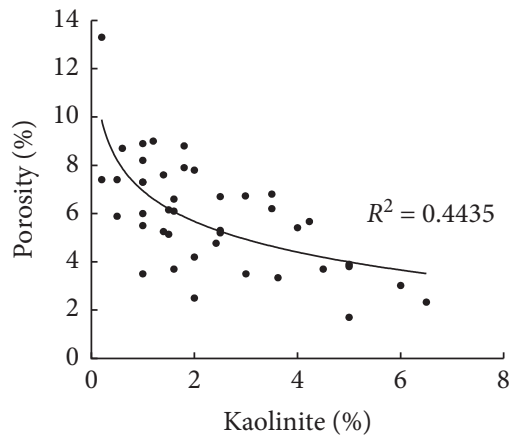

(c)

FIGURE 9: The relationships between diagenetic minerals and reservoir quality.

\section{Conclusions}

(i) The rock types of research area are mainly lithic arkose and feldspathic detritus quartz sandstone. Clay materials are mainly kaolinite, chlorite, and illite. Detrital components are dominated by quartz, followed by feldspar. The diagenetic stage is amidst stages A to B of the middle diagenetic stage.

(ii) The aimed sandstones belong to low-porosity-ultralow-permeability reservoirs. The main types of pore combination are dissolved pore-intergranular pore type, microporous type, intergranular poredissolved pore type, and intergranular pore type. The main types of throats are lamellar throats, and a small number of constricted throats also exist. The type of pore-throat combination is mainly mesopore-fine pore-fine throat type.

(iii) The development of Chang 2 reservoir in the Heshui area of the Ordos Basin is influenced by tectonism, sedimentation, and diagenesis. Small-scale noseshaped uplifts formed by tectonism form a good trap. The sorting of the sedimentary process has significant control over the porosity of the reservoir. The compaction, dissolution, and cementation effects during the diagenetic processes are relatively strong, which controls the evolution direction of the reservoir pores.

\section{Data Availability}

The experimental data used to support the findings of this study are included in the manuscript.

\section{Conflicts of Interest}

The authors declare that there are no conflicts of interest regarding the publication of this study.

\section{Acknowledgments}

The authors would like to acknowledge the financial support from the Shaanxi Natural Science Basic Research Program, China (2021JM-543 and 2021JQ-029), Open Fund of Key Laboratory of Coal Resources Exploration and Comprehensive Utilization, Ministry of Natural and Resources (KF2021-3 and KF2020-2), Shaanxi Provincial Key Research and Development Program (2021GY-140), Open Fund of Shaanxi Key Laboratory of Advanced Stimulation Technology for Oil \& Gas Reservoirs (20JS120), National Natural Science Foundation of China (51934005 and 52074226), and Young Science and Technology Talents Foundation of Shaanxi Province (2019KJXX-054). The authors thank Minghua Li from Xi'an Jiaotong University for his contributions to figure drawing. 


\section{Supplementary Materials}

Supplementary material contains Tables S1 to S3, which show the data of debris components, cement composition, and pore-throat structure parameters, respectively. (Supplementary Materials)

\section{References}

[1] A. K. Alhuraishawy, B. Bai, M. Wei, J. Geng, and J. Pu, "Mineral dissolution and fine migration effect on oil recovery factor by low-salinity water flooding in low-permeability sandstone reservoir," Fuel, vol. 220, pp. 898-907, 2018.

[2] Q.-X. Meng, W.-Y. Xu, H.-L. Wang, X.-Y. Zhuang, W.-C. Xie, and T. Rabczuk, "DigiSim-an open source software package for heterogeneous material modeling based on digital image processing," Advances in Engineering Software, vol. 148, Article ID 102836, 2020.

[3] J. Yan, X. He, S. Zhang et al., "Sensitive parameters of NMR $\mathrm{T}_{2}$ spectrum and their application to pore structure characterization and evaluation in logging profile: a case study from Chang 7 in the Yanchang formation, Heshui area, Ordos basin, NW China," Marine and Petroleum Geology, vol. 111, pp. 230-239, 2020.

[4] Z. L. Zhou, G. W. Wang, Y. Ran, J. Lai, Y. Cui, and X. Zhao, "A logging identification method of tight oil reservoir lithology and lithofacies: a case from Chang 7 member of Triassic Yanchang formation in Heshui area, Ordos basin, NW China," Petroleum Exploration and Development, vol. 43, no. 1, pp. 65-73, 2016.

[5] C. Zhu, M.-c. He, M. Karakus, X.-h. Zhang, and Z. Guo, "The collision experiment between rolling stones of different shapes and protective cushion in open-pit mines," Journal of Mountain Science, vol. 18, no. 5, pp. 1391-1403, 2021.

[6] J. Fan, X. Qu, C. Wang, Q. Lei, L. Cheng, and Z. Yang, "Natural fracture distribution and a new method predicting effective fractures in tight oil reservoirs in Ordos basin, NW China," Petroleum Exploration and Development, vol. 43, no. 5, pp. 806-14, 2016.

[7] C. Zhu, M. He, M. Karakus, X. Zhang, and Z. Tao, "Numerical simulations of the failure process of anaclinal slope physical model and control mechanism of negative Poisson's ratio cable," Bulletin of Engineering Geology and the Environment, vol. 80, no. 4, pp. 3365-3380, 2021.

[8] I. H. Falcon-Suarez, K. Amalokwu, J. Delgado-Martin, B. Callow, K. Robert, and L. North, "Comparison of stressdependent geophysical, hydraulic and mechanical properties of synthetic and natural sandstones for reservoir characterization and monitoring studies," Geophysical Prospecting, vol. 67, no. 4, pp. 784-803, 2019.

[9] Y. Bernabe, "Pore geometry and pressure dependence of the transport properties in sandstones," Geophysics, vol. 56, no. 4, pp. 436-446, 1991.

[10] Q. Wang, Z. Jiang, B. Jiang, H. Gao, Y. Huang, and P. Zhang, "Research on an automatic roadway formation method in deep mining areas by roof cutting with high-strength boltgrouting," International Journal of Rock Mechanics and Mining Sciences, vol. 128, Article ID 104264, 2020.

[11] K. Zhang, J. Lai, G. Bai et al., "Comparison of fractal models using NMR and CT analysis in low permeability sandstones," Marine and Petroleum Geology, vol. 112, Article ID 104069, 2020.

[12] Y. Wang, W. K. Feng, R. L. Hu, and C. H. Li, "Fracture evolution and energy characteristics during marble failure under triaxial fatigue cyclic and confining pressure unloading
(FC-CPU) conditions," Rock Mechanics and Rock Engineering, vol. 54, no. 2, pp. 799-818, 2021.

[13] J. Rouquerol, D. Avnir, C. W. Fairbridge et al., "Recommendations for the characterization of porous solids (technical report)," Pure and Applied Chemistry, vol. 66, no. 8, pp. 1739-1758, 1994.

[14] Q. Wang, Y. Wang, M. He et al., "Experimental research and application of automatically formed roadway without advance tunneling," Tunnelling and Underground Space Technology, vol. 114, Article ID 103999, 2021.

[15] L. M. Anovitz and D. R. Cole, "Characterization and analysis of porosity and pore structures," Reviews in Mineralogy and Geochemistry, vol. 80, no. 1, pp. 61-164, 2015.

[16] A. Li, F. Dai, Y. Liu, H. Du, and R. Jiang, "Dynamic stability evaluation of underground cavern sidewalls against flexural toppling considering excavation-induced damage," Tunnelling and Underground Space Technology, vol. 112, Article ID 103903, 2021.

[17] D. Ren, R. Li, D. Liu, Y. Li, N. Liu, and F. Yang, "Quantifying fractal dimension in integrated experimental data of tight sandstones," Geofluids, vol. 2019, Article ID 6463473, 19 pages, 2019.

[18] E. D. Pittman, "Diagenesis of quartz in sandstones as revealed by scanning electron microscopy," Journal of Sedimentary Research, vol. 42, no. 3, pp. 507-19, 1972.

[19] M. P. Fahy and M. J. Guccione, "Estimating strength of sandstone using petrographic thin-section data," Environmental \& Engineering Geoscience, vol. 16, no. 4, pp. 467-485, 1979.

[20] X. Li, J. Yao, H. Liu, X. Liu, L. Wei, and M. Feng, "Tectonic origin type of the low amplitude uplifted structure and its role in the control of the distribution of oil and gas in Mesozoic, the Ordos basin," Geoscience, vol. 27, no. 4, pp. 755-65, 2013.

[21] J.-q. Luo and Z.-m. He, "Tectonic evolution and oil-gas distribution in the Mesozoic Ordos basin," Geology and Resources, vol. 2, 2008.

[22] D. Liu, J. Su, Z. Gu, Y. Qi, F. Yang, and T. Tian, "Geochemical properties and pore structure control on oil extraction of shale," Lithosphere, vol. 2021, Article ID 6646791, 2021.

[23] M. Wang, H. Tang, S. Liu, F. Zhao, L. Li, and H. Lu, "Formation mechanism of differential sandstone densification modes and its impact on reservoir quality: a case study of upper paleozoic Permian in eastern part of Sulige gas field, Ordos basin," Journal of China University of Mining and Technology, vol. 6, pp. 1282-300, 2017.

[24] W. Zhang, L. Xie, W. Yang, Y. Qin, and P. a. Peng, "Micro fractures and pores in lacustrine shales of the upper Triassic Yanchang Chang 7 member, Ordos basin, China," Journal of Petroleum Science and Engineering, vol. 156, pp. 194-201, 2017.

[25] I. Martini and F. Sandrelli, "Facies analysis of a Pliocene riverdominated deltaic succession (Siena basin, Italy): Implications for the formation and infilling of terminal distributary channels," Sedimentology, vol. 62, no. 1, pp. 234-265, 2015.

[26] C. Zou, Z. Yang, H. Wang, D. Dazhong, L. Honglin, and S. Zhensheng, "Exploring petroleum inside source kitchen: Jurassic unconventional continental giant shale oil \& gas field in Sichuan basin, China," Acta Geologica Sinica, vol. 93, no. 7, pp. 1551-62, 2019.

[27] C. Zhang, D. Zhu, Q. Luo et al., "Major factors controlling fracture development in the middle Permian Lucaogou formation tight oil reservoir, Junggar basin, NW China," Journal of Asian Earth Sciences, vol. 146, pp. 279-295, 2017.

[28] Y. Zhou, D. Zhenchun, and W. Lihua, "Main factors controlling formation of dolomite reservoir underlying gypsum-salt layer in the 5th member of Ordovician Majiagou formation, Ordos basin," Oil \& Gas Geology, vol. 39, no. 6, pp. 1214-8, 2018. 